TURIZAM

Volume 16 , Issue 4

170-179 (2012)

\title{
Conference Attendees' Satisfaction: Evidence from Belgrade (Serbia)
}

Dunjić Jelena*, Dragićević Vanja*, Arsenović Daniela*, Pantelić Milana*, Stankov Uglješa*

Received: November 2012 | Accepted: December 2012

\begin{abstract}
Conference industry brings significant economic effects and that is one of the reasons why many destinations around the world strive to organize conferences, especially the international ones, which make bigger economic effects.

According to the Strategy of tourism development of the Republic of Serbia (2005-2015), city break and business tourism are tourism products of high priority, which can provide short-term positioning of Novi Sad and Belgrade, at the first place, at the international tourism market, and contribute to the growth of tourism turnover of foreign travellers.

Belgrade is the capital and the largest city in Serbia. It is very well equipped with necessary infrastructure for organizing business events such as conferences, congresses, meetings etc. Lately, the number of international business events in Serbia is increasing and the majority of those events are organized in Belgrade. However, there are very few surveys which are examining satisfaction of the conference attendees in Serbia. This topic is often ignored despite the fact that the attendees satisfaction is substantial for organizers and all other relevant stakeholders at host destination.

Therefore, the aim of this paper is to analyze the satisfaction of the conference attendees, as they are final consumers of conference tourist product and their experience regarding both conference and host destination is thus essential to destination marketing and management organizations, conference centres, hotel managers, meeting planners and all other stakeholders involved in conference industry and tourism.
\end{abstract}

Key words: conference attendee, satisfaction, conference destination

\section{Introduction}

The conference industry, as a part of business tourism sector, is globally recognized for its valuable economic contribution to tourism destination, as well as for social and cultural benefits to the destination, the exchange of ideas, the cultivation of business contacts, facilitation of technology transfers etc (Weber and Chon, 20O2).

* University of Novi Sad, Faculty of Sciences, Department of Geography, Tourism and Hotel Management, Trg Dositeja Obradovića 3, 21000 Novi Sad, Serbia; Corresponding author: vanja.dragicevic@dgt.uns.ac.rs 
According to the World Tourism Organization (WTO) about 30\% of international tourist movements belong to the so-called non-tourist movements including the conferences. The number of events per year in the ICCA (International Conference and Congress Association) Association Database has grown by almost 4,OOO events over the past IO years (2OO2-2OII) (ICCA Statistics Report 2002-2OII, International Association Meetings Market).

Development of conference industry requires a quality infrastructure necessary for congress organization and tourism offer, which will meet the needs of the attendees and organizers of meetings. According to Swarbrooke and Horner (2OOI), a business tourism destination has to offer a suitable venue for the meeting, sufficient accommodation (if a venue is nonresidential), attractions, good accessibility to the generating markets and efficient transport system within the destination.

Tourist destinations that have elements of attractiveness are also often desirable place for hosting various business events. The more attractive the destination is, the more attractive the event would be for potential attendees. The services provided in a destination and its

facilities are critical to the success of the meeting destination (Crouch and Weber, 2002).

Conference attendees are valuable assets for destination and tourism industry. They bring multi-economic benefits to the host location through their expenditure on different services (Oppermann and Chon, I997), they usually stay longer and spend more, they help in promoting host location and can provide a major source of shoulder and off-season demand, since most corporate and association meetings take place during spring and fall, the traditional soft periods in many tourist areas (Oppermann, I996; Zhanga et al, 2007).

Competition among conference destinations and venues has highlighted the need for the evaluation of the conference attendees' satisfaction, although relatively few studies have investigated variables that influence conference satisfaction (Oliver, I996; Severt et al, 2007; Kim et al, 2OO9; Lu and Cai, 2OII; Tanford et al, 2OI2; Dragićević et al, 2OIO; Dragićević et al, 2OII).

Zhanga et al. (2007) stated that the conference program itself can satisfy the attendees' needs by offering them an opportunity to keep up with any changes in their professional field, to hear respected experts in their field and to learn new skills. Similarly, in Severt et al. (2007) study, attendees who were happy with the educational benefits reported a stronger satisfaction with the conference and were more likely to return and to tell others to attend the conference.

Satisfaction for a mega-business event in Hong Kong, was evaluated by Bauer et al. (2008). Attendees were most satisfied with accessibility of Hong Kong, safety and security, tolerance of other cultures, quality of the exhibition, and cleanliness of destination. In Tanford et al (2OI2) study, five factors were found to influence convention attendance and satisfaction: program, networking, location, cost, and external activities. Satisfaction with convention activities (program and networking) were the only significant correlates of satisfaction, as these are "core" convention attributes, while other factors such as location, external activities, and costs are tangential to the convention experience and therefore less important in overall satisfaction. Program satisfaction was a key determinant of intentions to return in the future or switch to a different convention.

In Serbia there is little research about the satisfaction of conference attendees. In two studies (Dragićević et al., 2OIO; Dragićević et al, 2OII) attendee satisfaction with international conferences in Serbia was evaluated along three dimensions: venue, organization, and technical equipment, but there was no evaluation of destination attributes, which could contribute to a higher quality conference or unexpected experience for the attendees. 
Therefore, this study examines the international conference attendees' satisfaction with both conference related attributes, as they are primary motivator for conference attendance and a key determinant for conference satisfaction, and destination related attributes.

\section{Conference industry in Belgrade}

According to the Tourism Development Strategy of the Republic of Serbia (2005-20I5), the city and business tourism are the priority tourism products which can in the short term provide positioning, especially Belgrade and Novi Sad, and later other destination in the international tourism market, and thus contribute to increase tourist trade of foreign tourists.

In order to promote Serbia as a destination of business tourism, Serbia Convention Bureau was established as part of the Tourist Organization of Serbia in 2006. One year later the Belgrade Convention Bureau was opened (2007). In 2006 Belgrade was located on the 209th place in the ICCA rankings, with only 9 events. In 2OII Belgrade found at the 49th place in the world with 42 international events (ICCA Statistics Report 2002-2OII, International Association Meetings Market). Such positive results can be correlated with the establishment of the Convention Bureau of Serbia 2006, and Convention Bureau of Belgrade in 2007. Therefore, more attention was paid to the promotion of Serbia as a business tourism destination and sale of convention facilities.

Seminars, symposiums, conferences, trade shows and scientific and professional gatherings are organized throughout the year in the number of convention and exhibition facilities in Belgrade, including Sava Centre, Belgrade Fair, Belgrade Arena, and Belexpocentar.

Sava centre is the largest convention, cultural and business centre in the country and one of the largest in Europe, whose activities include the organization of conferences, all types of artistic events and all types of events in general. Belgrade Fair is the largest trade fair institution in Serbia. Belgrade Arena opened in 2004 as the largest and most modern complex of all types of mass sports, entertainment, cultural, trade fair and conference events.

Belgrade also has adequate hotels and facilities which are equipped with conference rooms. Convention Bureau also allocates specific venues in Belgrade for hosting business events, which can provide a unique atmosphere.

\section{Methodology}

A survey was conducted using a questionnaire on the Third International Conference of Geosciences and Environment. The study instrument was developed after an in-depth literature review on the topics related to conference attendees' satisfaction.

Questionnaire is divided into two parts. The first part consists of nine questions related to socio-demographic characteristics about respondents and about their activities during stay in Belgrade. The second part consists of fifteen questions related to their perception of the conference ( 7 conference attributes) and Belgrade as a host destination (8 destination attributes). In the second part, the respondents expressed opinions on the level of their satisfaction of cited elements of the conference and Belgrade as a destination using a five-point Likert scale, ranking from "very dissatisfied" (I) to "very satisfied" (5).

The conference was held at the "Continental" hotel in Belgrade from 27 to 3I May 2 OI2. The conference program was divided into two parts: on 27 and 28 May was held a profession- 
al conference, meeting professors-lecturers at the conference, while from 29 to 3I May students-participants gathered at the conference. The sample involved professors-lecturers at the conference, student participants and exhibitors who participated at the technical exhibition at the conference. The questionnaires were distributed through personal contact with respondents at the conference. There was 97 distributed questionnaires, and 75 respondents have completed them correctly. Some authors believe that the estimates by statistical methods will be good only if the sample contains a minimum of 5I units (Bagozzi, I98I). Taking into account the abovementioned, it can be concluded that the sample used in this study $(\mathrm{N}=75)$ is representative. The data was analyzed using Statistical Packages for Social Sciences (SPSS).

\section{Study results}

\section{Respondents profile}

In this part of the paper the demographic and travel profile of the sample will be analyzed. The sample contained slightly more males (54.7\%) than females (45.3\%). When it comes to the analysis of the age structure, respondents were divided into 4 groups. Most of the respondents belong to the age group of I8-25 years (72\%). This fact is not surprising because of the nature of the conference, whose participants were mostly undergraduate and graduate students. The lowest number of participants belongs to the age group of over 50 years.

According to the state of origin, participants were divided into 3 groups. The first group includes participants from the host country - Serbia, the second group includes participants from European countries, and the third from non-European countries. The largest percentage of participants came from the European countries - 76\%. The second most numerous were the participants from Serbia - I4.7\%, while the lowest number of participants were from non-European countries - 9.3\%.

Table 1. Demographic profile of the respondents

\begin{tabular}{|l|r|r|}
\hline Characteristics & Frequency & \multicolumn{2}{|c|}{$\%$} \\
\hline Gender & 41 & 54.7 \\
\hline Male & 34 & 45.3 \\
\hline Female & 54 & 72.0 \\
\hline Age group & 8 & 10.7 \\
\hline $18-25$ & 7 & 9.3 \\
\hline $26-35$ & 6 & 8.0 \\
\hline $36-50$ & \multicolumn{3}{|c|}{} \\
\hline Over 50 & 11 & 14.7 \\
\hline State of origin & 57 & 76.0 \\
\hline Serbia & 7 & 9.3 \\
\hline European country & \multicolumn{3}{|c|}{} \\
\hline Non-European country & 51 & 68.0 \\
\hline Education level & 24 & 32.0 \\
\hline Faculty & 75 & 100 \\
\hline Other (Master or PhD) & \multicolumn{3}{|c|}{} \\
\hline Total & \multicolumn{3}{|c|}{$\mid$} \\
\hline
\end{tabular}


By their education level, respondents holding a university degree are dominant making total of $68 \%$, followed by Master and PhD degree (32\%).

Due to the nature of the conference, which has primarily a scientific character, these results were expected. Since the students initiated the organization of this conference, it is expected that attendees were mostly younger people of I8 to 25 years old. The largest number of participants from European countries is also expected, primarily because of their relative proximity and good transport links with Serbia - Belgrade, and then because of the large investments of leading European countries (where participants come from) in science and education. A large percentage of highly educated respondents is again associated with the scientific character of the conference, and all other events in the business tourism which itself is referred to a highly educated clientele.

Number of realized overnight stays by the attendees during the conference in Belgrade ranges from 2 to IO. Given that the conference was divided in two parts, of which the first lasted two days, and the second 3 days, it is understandable that most of the attendees spent $4(27 \%)$ and 5 nights in Belgrade (27\%), followed by $22 \%$ of the attendees who stayed in Belgrade for 3 nights. Belgrade residents and visitors who didn't use the accommodation services make $9 \%$ of the total number of the respondents, while $3 \%$ of the respondents spent 7 -IO nights and those were persons who come from distant European countries such as Ukraine and Russia, as well as countries outside the European continent such as: USA, Australia, Indonesia, Azerbaijan and Kazakhstan.

The results of the analysis of types of accommodation that are used by conference attendees during their stay in Belgrade are as follows: $66 \%$ of respondents stayed in hostels (which is not surprising as students represent the largest number of respondents and attendees of the conference), $24 \%$ of the respondents (36-50 years or over 50 years lecturers and experts at the conference) used high quality hotel services, while $9 \%$ are Belgrade residents.

The most of the respondents $(75 \%)$ visited Belgrade tourist attractions at their own initiative.

Only 5\% of the respondents took part in an organized city tour. Organized tour of the city with all its attractions and appropriate presentation of its rich history, not only that enriches the content of staying of the conference attendees, but can contribute to conference attendees experience and satisfaction with destination selection. A certain percentage of conference attendees, namely I5\%, didn't visit the sights, and their stay was reduced solely to the conference program. It is assumed that these attendees were not sufficiently motivated or informed, or that they believed that Belgrade does not have the interesting tourist attractions. This data suggests that more attention should be paid to destination related activities (sightseeing) in order to provide enriched tourism product, but also to influence the improvement of the image of the destination.

\section{Results of descriptive statistical analysis}

In this section the results of descriptive statistical analysis related to conference attributes and conference destination attributes will be presented.

Of all the analyzed conference attributes, the lowest mean values ranging between "no opinion" and "satisfied" (from 3.40 to 3.57) have the attributes: technical support, organization of the conference, the overall quality of the conference and the conference venue. In an expectant manner, the highest rating was assigned to the conference program including lecturers' expertise, possibilities for gaining new knowledge and networking opportunities, which represent "core" conference attributes. 


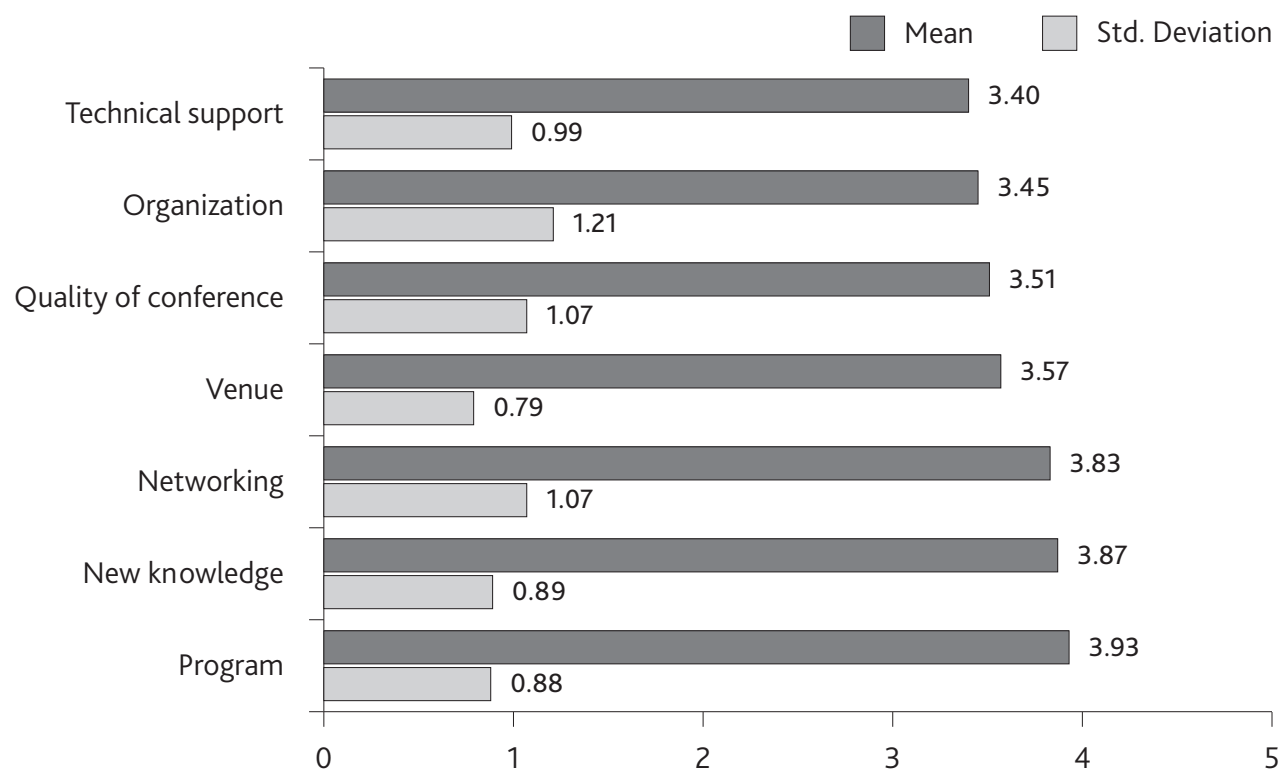

Figure 1. Mean values and standard deviation for conference attributes

Figure 2 shows the mean values and standard deviation of attributes related to Belgrade as a conference destination.

Generally, the attributes related to Belgrade as a conference destination are better rated than the conference attributes. As mean values of destination attributes are higher than 3.85 , it could be concluded that the respondents are generally satisfied with destination choice for the conference. The highest mean values (over 4) are assigned to the following attributes: gastronomy offer, quality of hotel services, cultural heritage of Belgrade and the overall

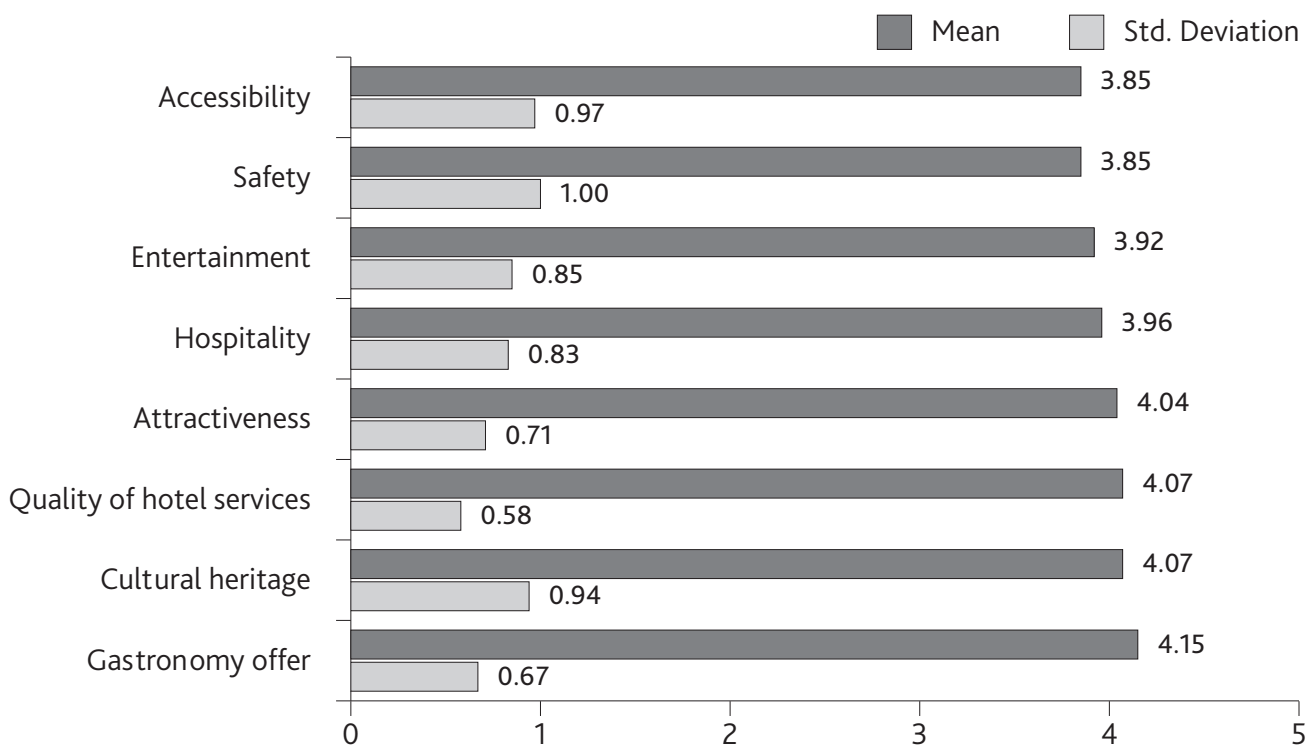

Figure 2. Mean values and standard deviation for destination attributes 
attractiveness of the destination, which can lead to conclusion that Belgrade is perceived by the respondents as an attractive destination.

Attributes such as hospitality of local residents, entertainment, safety level and accessibility are also evaluated with relatively high grades. Transit position of Serbia and Belgrade in the centre of it contributes significantly to the good transportation connections, but in the case of business events the existence of the airport in the city is the most important factor, and therefore a relatively good rates for traffic connection are not surprising.

Mean values of all conference attributes $(\mathrm{M}=3.65, \sigma=0.72)$ and destination related attributes $(M=3.99, \sigma=0.5 \mathrm{I})$ show that the respondents were more satisfied with the destination of the conference rather than with the conference related attributes which are primary motives for visiting destination. Therefore, in the future more attention should be paid to the overall quality of the conference.

\section{Results of T-Tests and the One-Way ANOVA}

To examine if certain groups of respondents differ according to their level of satisfaction with conference and destination attributes, the respondents were divided into groups according to gender, age, level of education and origin.

Independent samples t-test was used for testing differences in mean satisfaction between the respondents regarding their gender and educational level. The results indicate that there are no statistical relevant differences in mean satisfaction by the conference and destination attributes between two groups of respondents of different gender as well as between two groups of respondents holding university and Master/PhD degree (Table 2).

Table 2. Results of Independent Samples T-Test

\begin{tabular}{|c|c|c|c|c|c|c|c|}
\hline Variables & Gender & $\mathrm{N}$ & M & $\sigma$ & $t$ & df & $P$ \\
\hline \multirow{2}{*}{ Conference } & Male & 41 & 3.68 & 0.73 & \multirow{2}{*}{0.41} & \multirow{2}{*}{73} & \multirow{2}{*}{0.68} \\
\hline & Female & 34 & 3.61 & 0.71 & & & \\
\hline \multirow{3}{*}{ Destination } & Male & 41 & 4.05 & 0.49 & \multirow{2}{*}{1.23} & \multirow{2}{*}{73} & \multirow{2}{*}{0.22} \\
\hline & Female & 34 & 3.91 & 0.54 & & & \\
\hline & Education & $N$ & $M$ & $\sigma$ & $\mathrm{t}$ & df & $\mathrm{P}$ \\
\hline \multirow{2}{*}{ Conference } & Faculty & 51 & 3.59 & 0.76 & \multirow{2}{*}{-1.01} & \multirow{2}{*}{73} & \multirow{2}{*}{0.31} \\
\hline & MSc, PhD & 24 & 3.77 & 0.62 & & & \\
\hline \multirow{2}{*}{ Destination } & Faculty & 51 & 4.00 & 0.55 & \multirow{2}{*}{0.17} & \multirow{2}{*}{73} & \multirow{2}{*}{0.86} \\
\hline & MSc, PhD & 24 & 3.97 & 0.44 & & & \\
\hline
\end{tabular}

$M-$ mean value, $\sigma$-Std.Deviation, $t$ - value t statistics, $d f$ - divisions of sums of squares' deviations, $p$ - significance of $t$ statistics $(p<0.05)$

Regarding their age, the respondents were divided into four groups: I8-25, 26-35, 36-5O and over 50 years. Using the One-Way ANOVA method for investigation of significance of mean value differences, it may be concluded with 95\% accuracy that, between four groups of respondents of different age, there are no statistically significant differences in the level of respondents' satisfaction with the conference related attributes $(F=0.864 ; \mathrm{p}=0.464)$, nor with destination attributes $(\mathrm{F}=0.834, \mathrm{p}=0.48)$.

Also, One-Way ANOVA was applied for investigation of differences between three groups of respondents according to their origin. Results in Table 4 show that there is no statistical- 
Table 3. Compare Means - One-Way ANOVA. Dependent List: conference and destination attributes. Factor: age of the respondents

\begin{tabular}{|c|c|c|c|c|c|}
\hline Dependent List & Age & $M$ & $\sigma$ & $F$ & $\mathrm{P}$ \\
\hline \multirow{4}{*}{ Conference } & $18-25$ & 3.58 & 0.745 & \multirow{4}{*}{0.864} & \multirow{4}{*}{0.464} \\
\hline & $26-35$ & 3.88 & 0.838 & & \\
\hline & $36-50$ & 3.69 & 0.447 & & \\
\hline & over 50 & 3.98 & 0.530 & & \\
\hline \multirow{4}{*}{ Destination } & $18-25$ & 3.94 & 0.497 & \multirow{4}{*}{0.834} & \multirow{4}{*}{0.480} \\
\hline & $26-35$ & 4.14 & 0.599 & & \\
\hline & $36-50$ & 4.20 & 0.415 & & \\
\hline & over 50 & 4.02 & 0.654 & & \\
\hline
\end{tabular}

$M-$ mean value, $\sigma-S t d$. Deviation, $F$ - value F statistics, $p<0.05, F \geq 2.74$

Table 4. Compare Means - One-Way ANOVA. Dependent List: conference and destination attributes. Factor: origin of the respondents

\begin{tabular}{|l|l|r|r|r|}
\hline Dependent List & Origin & M & $\sigma$ & F \\
\hline Conference & Serbia & 3.92 & 0.640 & 1.334 \\
\hline & Europe & 3.58 & 0.734 & 0.270 \\
\hline & Out of Europe & 3.84 & 0.657 & \\
\hline Destination & Serbia & 4.09 & 0.596 & 0.329 \\
\hline & Europe & 3.96 & 0.502 & 0.721 \\
\hline & Out of Europe & 4.04 & 0.519 & \\
\hline
\end{tabular}

$M-$ mean value, $\sigma-S t d$.Deviation, $F$ - value F statistics, $p<0.05, F \geq 3.19$

ly significance between groups of respondents regarding their level of satisfaction with conference and destination attributes.

In order to test if there is statistically significant difference between mean values of respondents' satisfaction with conference and destination attributes, Paired Samples T-Test was used. The results show that there is a statistically significant difference between respondents' satisfaction with conference related attributes and respondents' satisfaction with destination attributes at 0.05 level $(\mathrm{p}=0.000 ; \mathrm{t}=-4.959)$. In other words, conference attendees are more satisfied with destination selection $(M=3.99)$ than with conference elements $(M=3.65)$.

This finding is also supported by respondents' opinion on two questions related to behavioural intentions regarding Belgrade as a destination: intention to recommend Belgrade as a conference destination and intention to revisit Belgrade.

Most of the respondents (84\%) said that they would recommend Belgrade as a conference destination and the majority of the conference attendees have a desire to re-visit Belgrade (86\%). Therefore, it can be concluded that Belgrade is perceived as an attractive destination for hosting conferences.

\section{Conclusion}

Belgrade is recognized as a primary destination in Serbia for hosting international events such as congresses, conferences, exhibitions and similar events, as this city has necessary infrastructure for holding events and it represent attractive tourist destinations. From 2006, 
when Serbia Convention Bureau opened and year later Belgrade Convention Bureau, the affirmation of conference industry started. Since then, it has been recording the increase in the number of meetings, conferences, congresses, as well as the number of tourists in Belgrade, particularly foreign tourists.

To continue this tendency in the future and to provide quality conference product, it is important for destination management organizations, hotels, congress centres and other venues hosting conferences, to conduct studies with the aim to examine conference attendees' satisfaction and behavioural intentions.

The research interpreted in this paper about the conference attendees' satisfaction was conducted in a hotel on accidental sample, consisting of conference attendees, who voluntary took part in the research. Based on the results obtained in analysis of the attendees' satisfaction with the conference related attributes, it is obvious from the mean score $(\mathrm{M}=3.65)$ that the attendees are not completely satisfied with the conference in general and specifically with some conference attributes, which are related to the technical support, the organization and the conference venue. Therefore, it can be concluded that the organizer should pay more attention to the venue selection process, as it affects overall quality of the conference. The conference program, as well as the opportunities for networking and gaining new knowledge are rated as satisfactory. However, it was surprising that higher rating was assigned to destination attributes compared to conference attributes. This difference between respondents' satisfaction with conference related attributes and respondents' satisfaction with destination attributes was found statistically significant. Also, the majority of the respondents show interest in visiting Belgrade again and would recommend Belgrade as a conference destination.

The results of T-tests and One way ANOVA show that there are no statistically significant differences in the level of respondents' satisfaction with the conference related attributes, nor with destination attributes between groups of respondents of different gender, age, education level and origin, meaning that all the respondents expressed similar opinions regarding the conference and destination attributes.

Based on the abovementioned results, the conclusion may be drawn that the respondents were satisfied with destination choice and they found Belgrade an attractive destination. This research, as well as many other studies, confirms that consumer satisfaction might lead to favourable word-of-mouth and to repeat visit to a destination.

Many previous studies show that networking, gaining new knowledge and conference program are key factors that influence conference attendance. But this study take these factors one step further by analyzing satisfaction with the same attributes adding destination related attributes. In this study the authors try to emphasize the importance of destination related attributes for the overall conference attendees' satisfaction. Therefore, the results are valuable for destination management organizations, hotel and congress centre managers, and specifically to professional conference organizers.

Similar studies, about experience, satisfaction, behavioural intentions and loyalty of conference attendees and meeting planners, should be undertaken periodically in hotels, congress centre and other conference venues in Belgrade, in order to improve quality of services, destination competitiveness and effectively promote Belgrade as an attractive conference destination. 


\section{Acknowledgment}

This paper is part of the project No. II4-45I-2644/2OI2-OI funded by the Provincial Secretariat for Science and Technological Development of the Vojvodina Province, Serbia.

\section{References}

Bagozzi, R. P. (198I). Evaluating Structural Equation Models with Unobservable Variables and Measurement Error: A Comment. Journal of Marketing Research, I8, 380.

Bauer, T., Law, R., Tse, T. And Weber, K. (2008). Motivation and satisfaction of megabusiness event attendees: The case of ITU telecom world 2006 in Hong Kong. International Journal of Contemporary Hospitality Management, 2O(2), 228-234.

Crouch, G., I., and Weber, K. (20O2). Marketing of convention tourism. In Convention tourism international research and industry perspectives, edited by Karin Weber and Kaye Chon. New York: Haworth Press Inc.

Dragićević, V., Blešić, I. and Stankov, U. (2OIO). Satisfaction and Behavioral Intentions of Congress Attendees: Evidence from an International Congress in Novi Sad (Serbia), Geographica Pannonica I4, I, 23 - 30.

Dragićević, V., Stankov, U., Armenski, T. and Štetić, S. (2OII). Evaluation of congress performance and congress attendees' satisfaction - a case study of Novi Sad (Serbia), Tourism and Hospitality Management, I7(I), 67-78.

ICCA Statistics Report 20O2-2OII, International Association Meetings Market

Kim, Y. S., Lee, Y. Y. And Love, C. (2009). A case study examining the influence of conference food functions on attendee satisfaction and return intention at a corporate conference. Journal of Convention \& Event Tourism, IO (3), 2II-23O.

Lu, T., and Cai, L. A. (2OII). An analysis of image and loyalty in convention and

exhibition tourism in China. Event Management, I5(I), 37-48.

Oliver, R. L. (I996). Satisfaction: A behavioural perspective on the consumer. McGraw-Hill Publishing Company.

Oppermann, M. (1996). Convention destination images: Analysis of association meeting planners' perceptions. Tourism Management I7(3), 75-I82

Oppermann, M. and Chon, K. S. (I997). Convention participation decision-making process. Annals of Tourism Research, 24(I), I78-I9I.

Severt, D., Wang, Y., Chen, P. and Breiter, D. 2007. Examining the motivation, perceived performance and behavioral intentions of convention attendees: Evidence from a regional conference. Tourism Management 28, 399-408.

Swarbrooke, J. and Horner, S. (2OOI): Business Travel and Tourism, Butterworth-Heinemann.

Tanford, S., Montgomery, R. and Nelson, K. B. (2OI2). Factors that Influence Attendance, Satisfaction, and Loyalty for Conventions. Journal of Convention \& Event Tourism, I3, 4, 290-3I8.

The Strategy of Tourism Development of the Republic of Serbia 2005-20I5.

Weber, K. and Chon, K. 20O2. Convention tourism international research and industry perspectives, Haworth Press Inc.,U.S.

Zhanga, H. Q., Leunga, V. and Qu, H. (2007). A refined model of factors affecting convention participation decision-making. Tourism Management 28, II23-II27. 